\title{
Electrical and Magnetic Properties of Quaternary Rare Earth Thiophosphate: $\mathrm{K}_{4} \mathrm{Sm}_{2}\left[\mathrm{PS}_{4}\right]_{2}\left[\mathrm{P}_{2} \mathrm{~S}_{6}\right]$
}

\author{
Víctor Manríquez, ${ }^{* a}$ Antonio Galdámez, ${ }^{a}$ Andrea Cerda-Monje, ${ }^{a}$ Octavio Peña ${ }^{b}$ and Ricardo E. Ávila \\ ${ }^{a}$ Departamento de Química, Facultad de Ciencias, Universidad de Chile, Casilla 653, Santiago, Chile \\ ${ }^{b}$ Sciences Chimiques de Rennes, UMR 6226, Université de Rennes 1, 35042 Rennes cedex, France \\ 'Departamento de Materiales Nucleares, Comisión Chilena de Energía Nuclear, Casilla 188-D, Santiago, Chile
}

\begin{abstract}
O tiofosfato quaternário de metal alcalino e terra rara $\mathrm{K}_{4} \mathrm{Sm}_{2}\left[\mathrm{PS}_{4}\right]_{2}\left[\mathrm{P}_{2} \mathrm{~S}_{6}\right]$ foi sintetizado pelo método cerâmico e caracterizado por difratometria de raios X de pó (XRD), microscopia eletrônica de varredura com microanálise de raios X (SEM-EDX), medidas de impedância eletroquímica e medidas magnéticas. A estrutura cristalina consiste de camadas de ${ }^{2} \infty \mathrm{Sm}_{2}\left[\mathrm{PS}_{4}\right]_{2}\left[\mathrm{P}_{2} \mathrm{~S}_{6}\right]^{4-}$ separadas por cátions $\mathrm{K}^{+}$. As medidas de condutividade elétrica indicam que o composto é um semicondutor com uma resistividade de $1,0 \times 10^{11} \Omega \mathrm{cm}$. O momento magnético, obtido a partir de $\chi^{-1}$ versus $\mathrm{T}$ a baixa temperatura, é igual a $0,57 \mu_{\mathrm{B}}$.
\end{abstract}

The quaternary alkali metal, rare earth thiophosphate phase $\mathrm{K}_{4} \mathrm{Sm}_{2}\left[\mathrm{PS}_{4}\right]_{2}\left[\mathrm{P}_{2} \mathrm{~S}_{6}\right]$ was synthesized by ceramic method and characterized by powder X-ray diffraction (XRD), SEM-EDX scanning electron microscope-microprobe analyses, electrochemical impedance and magnetic measurements. The crystal structure consists of layers of ${ }^{2} \infty \mathrm{Sm}_{2}\left[\mathrm{PS}_{4}\right]_{2}\left[\mathrm{P}_{2} \mathrm{~S}_{6}\right]^{4-}$ separated by $\mathrm{K}^{+}$cations. The electrical conductivity measurements indicate that the compound is a semiconductor with a resistivity of $1.0 \times 10^{11} \Omega \mathrm{cm}$. The magnetic moment, evaluated from $\chi^{-1}$ versus $\mathrm{T}$ at low temperature is $0.57 \mu_{\mathrm{B}}$.

Keywords: thiophosphate, electrical properties, magnetic properties

\section{Introduction}

The study on chalcophosphates of the type $\mathrm{AM}_{\mathrm{X}} \mathrm{P}_{\mathrm{Y}} \mathrm{Q}_{\mathrm{Z}}$ (where $\mathrm{A}$ and $\mathrm{M}$ are metals and $\mathrm{Q}=\mathrm{S}, \mathrm{Se}$ ) deserves a strong attention due to their anisotropic physical properties, as thermoelectric and nonlinear optics behaviors. ${ }^{1-5}$ Moreover, these phases present a great variety of structures in the solid state. A structural representation considers them as salts formed by the ions $\mathrm{A}^{+} \mathrm{M}^{\mathrm{m}+}$ and $\mathrm{P}_{\mathrm{Y}} \mathrm{Q}_{\mathrm{Z}}{ }^{\mathrm{n}-}$. They possess the structural anionic units $\mathrm{P}_{\mathrm{Y}} \mathrm{Q}_{\mathrm{Z}}{ }^{\mathrm{n}-}$, with chalcogenphosphorus bonds, coordinated to the metals $\mathrm{A}$ and $\mathrm{M}$ through chalcogen atoms $\mathrm{Q}$. The present investigation on chalcophosphate compounds has been oriented to the synthesis of quaternary phases to form salts, taking advantage of the flexibility and stability of the anions $\mathrm{P}_{\mathrm{Y}} \mathrm{Q}_{\mathrm{Z}}{ }^{\mathrm{n}-}(\mathrm{Q}=\mathrm{S}, \mathrm{Se})$ and their capability to form compounds with cations in several oxidation states.

Many quaternary rare-earth metal thiophosphates have been prepared and characterized structurally.
Examples of reported rare-earth thiophosphates include phases such as: $\mathrm{K}_{6} \mathrm{Yb}_{3}\left(\mathrm{PS}_{4}\right)_{5}{ }^{6}{ }^{6} \mathrm{Li}_{9} \mathrm{Nd}_{2}\left(\mathrm{PS}_{4}\right)_{5},{ }^{7} \mathrm{~K}_{3} \mathrm{Gd}_{3}\left(\mathrm{PS}_{4}\right)_{4}$ and $\mathrm{K}_{9} \mathrm{Gd}\left(\mathrm{PS}_{4}\right){ }_{4},{ }^{8} \mathrm{~K}_{3} \mathrm{CeP}_{2} \mathrm{~S}_{8},{ }^{9} \mathrm{Na}(\mathrm{RE}) \mathrm{P}_{2} \mathrm{~S}_{6}(\mathrm{RE}=\mathrm{Y}, \mathrm{Sm})$ and $\mathrm{KSmP}_{2} \mathrm{~S}_{7},{ }^{10} \mathrm{~K}_{2} \mathrm{NdP}_{2} \mathrm{~S}_{7},{ }^{11} \mathrm{KErP}_{2} \mathrm{~S}_{7}, \mathrm{NaErP}_{2} \mathrm{~S}_{6}$ and $\mathrm{Cs}_{3} \mathrm{Er}_{5}\left(\mathrm{PS}_{4}\right)_{6}{ }^{12}$ and $\mathrm{Li}_{9} \mathrm{Gd}_{2}\left(\mathrm{PS}_{4}\right)_{5}{ }^{13}$ These compounds present $\left[\mathrm{PS}_{4}\right]^{3-},\left[\mathrm{P}_{2} \mathrm{~S}_{6}\right]^{4-}$ and $\left[\mathrm{P}_{2} \mathrm{~S}_{7}\right]^{4-}$ anions coordinated to the metal rare-earth ions through sulfur atoms.

In the course of our work on quaternary heterocharged metal thiophosphates we have previously reported the crystal structures of the layered phases $\mathrm{KMP}_{2} \mathrm{~S}_{6}$ $(\mathrm{M}=\mathrm{Bi}, \mathrm{Sb})^{14,15}$ and the $\alpha$ - and $\beta$-phases of $\mathrm{NaSbP}_{2} \mathrm{~S}_{6}{ }^{16}$ In these phases the layers are formed by ethane-like anions $\left[\mathrm{P}_{2} \mathrm{~S}_{6}\right]^{4-}$ bridging the $\mathrm{M}^{3+}$ metal atoms, which are held together by layers of alkali cations. Our investigation of quaternary systems containing alkali metals, rare-earths (3+), phosphorus and sulfur has yielded a new samarium thiophosphate: $\mathrm{K}_{2} \mathrm{SmP}_{2} \mathrm{~S}_{7}$, which contains the anionic units $\left[\mathrm{P}_{2} \mathrm{~S}_{6}\right]^{4-}$ and $\left[\mathrm{PS}_{4}\right]^{3-} .{ }^{17}$ We report herein the electrical and magnetic properties of this quaternary samarium thiophosphate compound.

*e-mail: vmanriqu@uchile.cl 


\section{Experimental}

The preparation of the phase $\mathrm{K}_{2} \mathrm{SmP}_{2} \mathrm{~S}_{7}$ was carried out by direct combination, in stoichiometric amounts, of powders of the corresponding high purity elements $(99.99 \%$, Aldrich). The reaction mixture was sealed in evacuated quartz ampoules and placed in a programmable furnace. All manipulations were carried out under $\mathrm{Ar}$ atmosphere. The mixture was heated to $800{ }^{\circ} \mathrm{C}$ at $10{ }^{\circ} \mathrm{C} \mathrm{h}^{-1}$. After five days, the reacted matter was slowly cooled to room temperature at a rate of $6{ }^{\circ} \mathrm{C} \mathrm{h}^{-1}$. The ampoule was opened to reveal a formation of yellow crystals. The reaction mixture was washed with DMF and anhydrous ether. (Found values: $\mathrm{K}, 15.66$; $\mathrm{Sm}, 29.43 ; \mathrm{P}, 11.22 ; \mathrm{S}, 43.69 \%$. Calculated values: K, 15.19; Sm, 29.20; P, 12.03; $\mathrm{S}, 43.58 \%)$. The product appeared to be air and moisture stable over several weeks.

The X-ray diffraction (XRD) data were collected at room temperature with a Siemens D-5000 X-ray powder diffractometer, using $\mathrm{Cu}-\mathrm{K}_{\alpha}$ radiation in the range $5^{\circ}<2 \theta<60^{\circ}$. Qualitative comparison of the experimental powder pattern with calculated powder pattern of known crystal structure was performed. ${ }^{17}$ Elemental analysis confirming the chemical composition of the powder was obtained from energy dispersive spectroscopy (EDS) on a JEOL 6400 scanning electron microscope system equipped with an Oxford LinK ISIS microanalyzer. Differential thermal analysis (DTA) and thermogravimetric analysis (TGA) were performed on a Rheometric Scientific STA 1500H/625 thermal analysis system. The DTA/TGA curves were run simultaneously on each sample from room temperature to $1000{ }^{\circ} \mathrm{C}$, in flowing nitrogen at a heating rate of $10{ }^{\circ} \mathrm{C} \mathrm{min}{ }^{-1}$.

The electrical properties were studied by $d c$ currentvoltage measurements using a Keithley model 237 sourceelectrometer and by impedance-frequency analysis using a Solartron Instruments model 1260 analyzer. $156.5 \mathrm{mg}$ of powder were pressed at $c a .3 .92$ tons (927 MPa) for $30 \mathrm{~s}$, resulting in a pellet of $7.27 \mathrm{~mm}$ diameter and thickness of $1.35 \mathrm{~mm}$, corresponding to an average density of $2.79 \mathrm{~g} \mathrm{~cm}^{-3}$. Gold electrodes, $10 \mathrm{~nm}$ thick, were deposited by sputtering.

The magnetic measurements were performed on a Quantum Design MPMS XL5 SQUID magnetometer, under a static field of $2.5 \mathrm{kOe}$ and with increasing temperatures from $2 \mathrm{~K}$ up to $300 \mathrm{~K} .134 .9 \mathrm{mg}$ of powdered sample were placed inside a gelatin capsule, of which the diamagnetic contribution (less than 3\% at room temperature) was subtracted from the overall signal.

\section{Results and Discussion}

We have previously reported the crystal structures of the layered phases of a new samarium thiophosphate $\mathrm{K}_{4} \mathrm{Sm}_{2}\left[\mathrm{PS}_{4}\right]_{2}\left[\mathrm{P}_{2} \mathrm{~S}_{6}\right] \cdot{ }^{17} \mathrm{~A}$ description of the structure is briefly recalled here. The phase $\mathrm{K}_{2} \mathrm{SmP}_{2} \mathrm{~S}_{7}$ has a two-dimensional layered structure as shown in Figure 1. The layered structure contains $\mathrm{Sm}^{3+}$ ions coordinated by three $\left[\mathrm{PS}_{4}\right]^{3-}$ and one $\left[\mathrm{P}_{2} \mathrm{~S}_{6}\right]^{4-}$ anions. There are two crystallographically different $\mathrm{K}^{+}$cations coordinated to $\mathrm{S}$ atoms. The packing of $\mathrm{K}_{2} \mathrm{SmP}_{2} \mathrm{~S}_{7}$ is formed by $\left[\mathrm{Sm}_{2}\left[\mathrm{PS}_{4}\right]_{2}\left[\mathrm{P}_{2} \mathrm{~S}_{6}\right]\right]^{4-}$ layers, in the $a b$-plane, separated by $\mathrm{K}^{+}$cations.

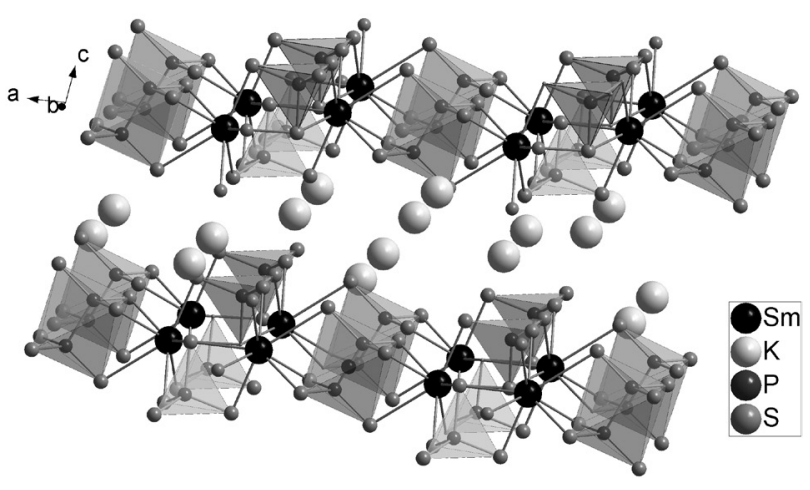

Figure 1. Crystal structure of $\mathrm{K}_{2} \mathrm{SmP}_{2} \mathrm{~S}_{7}$ down the b-axis.

The monolayer of $\mathrm{Sm}^{3+}$ cations arrangement can be seen as a graphite-like configuration in the zig-zag chain pattern, as shown in Figure 2. The closest $\mathrm{Sm}$-Sm distance within the layers is $5.307 \AA$.

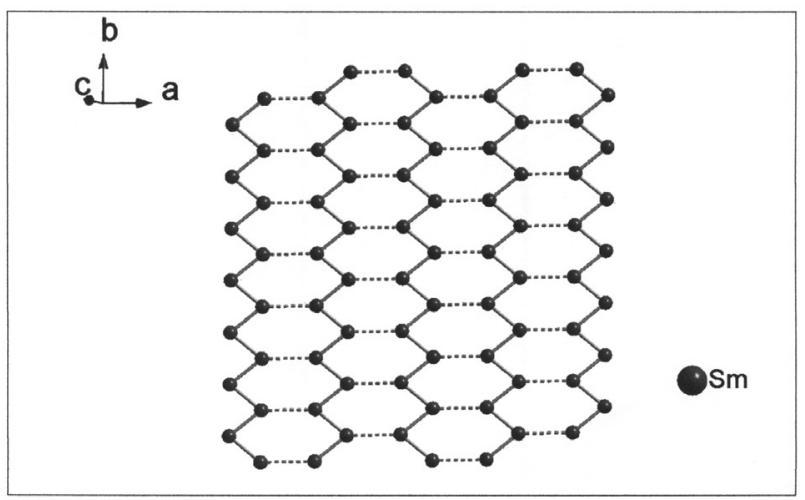

Figure 2. Arrangement of $\mathrm{Sm}^{3+}$ cations in one layer.

The X-ray powder diffractograms (XRD) of the $\mathrm{K}_{2} \mathrm{SmP}_{2} \mathrm{~S}_{7}$ phase show sharp lines that reflect the crystallinity and homogeneity. The XRD was completely indexed, and the observed interplanar spacing showed a good agreement with that calculated from the crystal structure. ${ }^{17}$ Elemental analysis was carried out, which, together with the sharp XRD pattern, evidences the purity of the studied samples. 
The differential thermal and thermogravimetric analyses (DTA/TGA) showed a slight weight loss of approximately $5 \%$ in the interval $37-550{ }^{\circ} \mathrm{C}$, which may be assigned to partial sulfur loss. Then, the mass continues to reduce until the temperature reaches $1000^{\circ} \mathrm{C}$. The DTA exhibited a sharp exothermic peak at $550^{\circ} \mathrm{C}$. These results are shown in Figure 3. The first stage of decomposition can be attributed to the partial sulfur loss. In a second stage, at $550^{\circ} \mathrm{C}$, the thiophosphate phase decomposes to sulphides and phosphides, which were identified by XRD analysis of the residues.

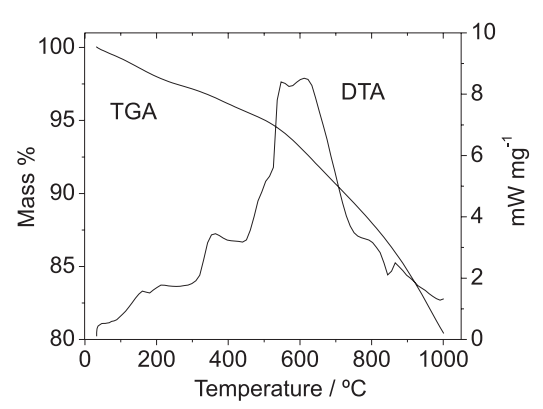

Figure 3. DTA/TGA profiles of $\mathrm{K}_{2} \mathrm{SmP}_{2} \mathrm{~S}_{7}$.

Before electrical characterization the pellet was mounted in the test chamber, and the assembly was evacuated (below $10^{-4} \mathrm{mbar}$ ) for $1 \mathrm{~h}$, at ambient temperature. Cycling the bias over $\pm 100 \mathrm{~V}$ at $1 \mathrm{~V} \mathrm{~s}^{-1}$ leads to a hysteresis of $0.41 \mathrm{nA}$, at $\mathrm{V}=0$, between the negative-going and the positive-going branches at $312 \mathrm{~K}$. This amount to $3.8 \%$ of the current span from -100 to $+100 \mathrm{~V}$. Otherwise, the I-V curves are essentially linear. At higher bias, sweeping from -100 to $+1100 \mathrm{~V}$, the I-V curves bend slightly upwards, conforming to a space-charge limited current model, $\left(I \sim V^{n}\right)$, with $n=1.13$ over the 100 to $1100 \mathrm{~V}$ range. The resistance of $3.29 \times 10^{10} \Omega$, in the $\pm 100 \mathrm{~V}$ range, corresponds to a resistivity of $1.0 \times 10^{11} \Omega \mathrm{cm}$. Temperature variations over a narrow range (ambient to $313 \mathrm{~K}$ ) indicates a semiconductorlike temperature dependence of the resistivity.

The impedance $(R+j X)$-frequency measurements, where $j=(-1)^{1 / 2}$ (Figure 4), display approximately one half of a semicircle in the Nyquist plot. Data scatter, due to high impedance, restricts the measurements to frequencies above $1 \mathrm{~Hz}$. These data have been analyzed using the equivalent circuit program, by B. Boukamp (version 2.0), assuming the parallel combination of a resistor $(\mathrm{R})$, a constant phase element (CPE, of impedance $\left(Y_{0}(j \omega)^{n}\right)^{-1}$, where $\omega$ is the angular frequency), and a carrier diffusion process with permeable boundaries ${ }^{18}$ (of impedance $\tanh \left(B(j \omega)^{1 / 2}\right.$ ) $\left(Y_{\mathrm{o}}^{\prime}(j \omega)^{1 / 2}\right)^{-1}$. Assuming permeable boundaries, with $\mathrm{Pt}$ electrodes, implies assuming electronic conduction as the dominant charge transport process.

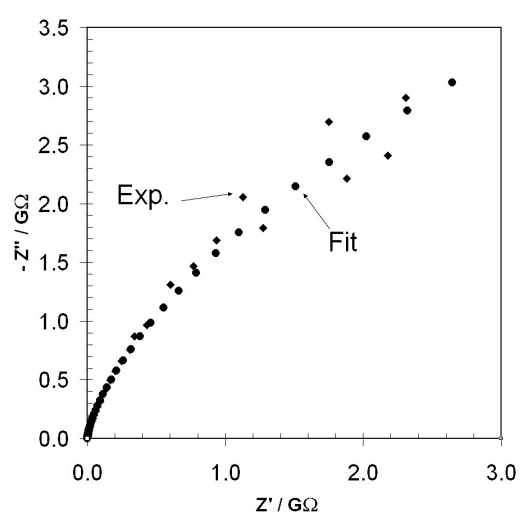

Figure 4. Impedance-frequency measurement. Average of 5 measurements, taken at $313.3 \mathrm{~K}$.

The fit achieves a $\chi^{2}$ quality of $1.9 \times 10^{-3}$, with values of $R=2.3 \times 10^{10}( \pm 20 \%) \Omega, Y_{\mathrm{o}}=2.12 \times 10^{-12}( \pm 4 \%) \mathrm{pFs}^{\mathrm{n}-1}$, $n=0.976( \pm 0.3 \%), Y_{\mathrm{o}}^{\prime}=2.8 \times 10^{-11}( \pm 4 \%) \Omega^{-1}$, and $B=0.6$ $( \pm 87 \%) \mathrm{s}^{1 / 2}$. The value of $R$, together with the parameters of the CPE, and an estimate of the frequency at which the maximum of $(-X)$ would occur, lead to a value of 8 for the effective relative dielectric permittivity, ${ }^{19}$ suggesting that the charge transport belongs to the interior of the material grains. This is supported too by the value of $n$, so close to 1 , indicating that the charge transport is rather homogeneous, i.e., there is not a complex network of carrier paths, as would be the case for intergrain transport. Whithin this interpretation, the value of $\mathrm{R}$ corresponds to a bulk resistivity of $1.0 \times 10^{11} \Omega \mathrm{cm}$, and it accounts for approximately two thirds of the $d c$ resistance $\left(3.3 \times 10^{10} \Omega\right)$. The remaining resistance is due, most likely, to the transport at intergrain boundaries. This expectation comes from the loose arrangement of grains in the pellets, which were not sintered after pressing, since that process would degrade the material. The resulting scant grain-to-grain contact should lead to high intergrain impedance. Finally, the parameters of the diffusion model depend ${ }^{20}$ on the diffusion length, the diffusion coefficient, and on the response of the carrier concentration upon the oscillating electrodes potential. These factors are fully beyond the scope of current work, so, the parameters $B$ and $Y_{o}^{\prime}$ ' have not been related to physical properties of the material.

The band gap analysis, using UV-Vis diffuse reflectance spectroscopy, indicates that $\mathrm{K}_{2} \mathrm{SmP}_{2} \mathrm{~S}_{7}$ has an energy band gap of $2.59 \mathrm{eV} .{ }^{17}$ These values are expected for yellow compounds. For comparison, the corresponding band gaps of $\mathrm{NaSmP}_{2} \mathrm{~S}_{6}$ is $2.54 \mathrm{eV} .^{10}$

Figure 5 shows the thermal dependence of the product [susceptibility*temperature]. The temperature-independent contribution to the magnetic susceptibility, as deduced from the slope of the $\chi^{*}$ T versus $\mathrm{T}$ plot, is due to the admixture between the ${ }^{6} \mathrm{H}_{5 / 2}$ and the ${ }^{6} \mathrm{H}_{7 / 2}$ multiplets of the $\mathrm{Sm}^{3+}$ ion 
and it is known as the Van Vleck susceptibility, $\chi_{\mathrm{VV}}{ }^{20,21} \mathrm{~A}$ value for $\chi_{\mathrm{VV}}$ of $2.98 \times 10^{-3} \mathrm{emu} \mathrm{mol}^{-1}$ was estimated in the high-temperature linear region (150-300 K) in Figure 5. The Figure 6 shows the experimental magnetic susceptibility (black dots) and the one obtained after subtraction of the temperature-independent paramagnetic Van Vleck $\chi_{\mathrm{VV}}$ term (open symbols).

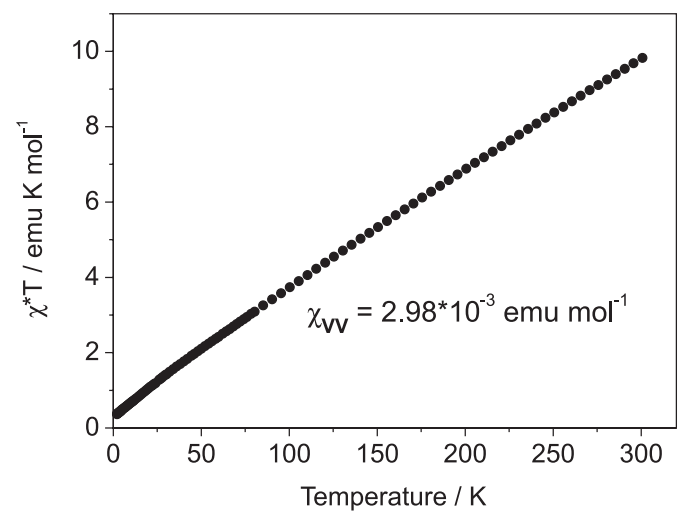

Figure 5. $\chi^{* \mathrm{~T}}$ versus $\mathrm{T}$ diagram: Van Vleck term $\left(\chi_{\mathrm{VV}}\right)$ was estimated in the high temperature range $(150 \leq \mathrm{T} \leq 300 \mathrm{~K})$.

Assuming that at low temperature the ${ }^{6} \mathrm{H}_{5 / 2}$ level is situated far from the higher energy states, an estimation of the effective magnetic moment can be done at the lowest available temperature range. For this, we have plotted in the insert of Figure 6 the inverse magnetic susceptibility of the corrected data. These data extrapolate to $\mathrm{T}=0$, which means that no magnetic interactions can be expected between $\mathrm{Sm}$ spins. The low temperature slope can be considered then as a good approximation to the effective magnetic moment. In our case, we have taken the data in the range between 2 and $15 \mathrm{~K}$ (insert, Figure 6) and calculated a magnetic moment of $0.57 \mu_{\mathrm{B}}$ which corresponds quite reasonably to the expected moment for non correlated $\mathrm{Sm}^{3+}$ spins ( $\mu^{\text {theo }}$ $\left.=g \sqrt{J(J+1)}=0.85 \mu_{\mathrm{B}} ; g=2 / 7\right)$. This result excludes the possibility of a divalent oxidation state for samarium which will give a null moment $\left(\mathrm{Sm}^{2+} ;{ }^{7} \mathrm{~F}_{0}\right.$ state, $\left.\mathrm{g}=\mathrm{J}=0, \mu_{\text {eff }}=0\right)$. We confirm then that samarium is at its +III oxidation state, with a large Van Vleck contribution due to the admixture of the fundamental state with higher energy levels.

\section{Conclusions}

In summary, we have prepared quaternary alkali rare earth thiophosphate phase $\mathrm{K}_{4} \mathrm{Sm}_{2}\left[\mathrm{PS}_{4}\right]_{2}\left[\mathrm{P}_{2} \mathrm{~S}_{6}\right]$ by ceramic method. The thermal stability was verified and no phase transition was observed. The current-voltage characteristics and their temperature dependence over a narrow temperature range indicate semiconductor temperature activation of the conductivity. The electrochemical impedance

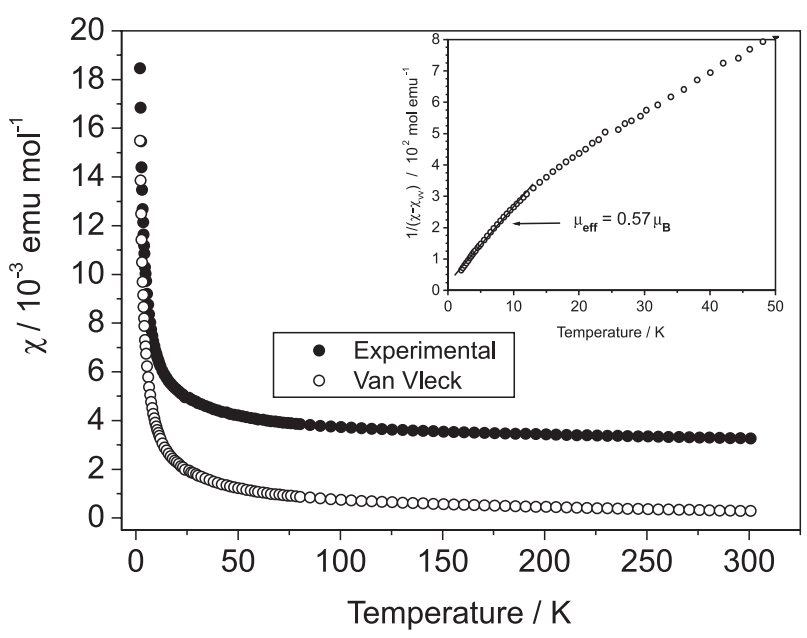

Figure 6. Magnetic susceptibility measured under $2.5 \mathrm{kOe}$ : filled symbols represent the experimental data; empty symbols show data after correction of a Van Vleck term $\left(\chi_{\mathrm{vv}}\right)$. The insert shows the corrected inverse susceptibility and an estimation of the effective magnetic moment on the low temperature range.

measurements indicate that the bulk (interior) of the compound grains present a resistivity of $1.0 \times 10^{11} \Omega \mathrm{cm}$, and effective relative dielectric permittivity of 8 , suggesting a dependence on bulk, intragrain charge transport. Magnetic measurement indicated that samarium is at its +III oxidation state, with an evident admixture of the fundamental ${ }^{6} \mathrm{H}_{5 / 2}$ state with higher energy levels.

\section{Acknowledgements}

This work was supported by FONDECYT through operating grant $\mathrm{N}^{\circ} 1061116$.

\section{References}

1. Moller, H. J.; Semiconductor for Solar Cell; Artech House: Boston, 1993.

2. Borkowski, K.; Pyzyluski, J.; Mater. Res. Bull. 1987, 22, 381.

3. Bridenbaugh, P. M.; Mater. Res. Bull. 1973, 8, 1055.

4. Carpentier, C. D.; Nitsche, R.; Mater. Res. Bull. 1974, 9, 1097.

5. Arnautova, E.; Sviridov, E.; Rogach, E.; Savchenko, E;. Grekov, A.; Integr. Ferroelectr. 1992, 1, 147.

6. Aitken, J. A.; Kanatzidis, M. G.; J. Am. Chem. Soc. 2004, 126, 11780.

7. Komm, T.; Strobel, S.; Schleid, T.; J. Alloys Compd. 2006, 418, 106.

8. Komm, T.; Strobel, S.; Schleid, T.; J. Alloys Compd. 2008, 451, 648.

9. Gauthier, G.; Jobic, S.; Brec, R.; Rouxel, J.; Inorg. Chem. 1998, 37, 2332.

10. Goh, E-Y.; Kim, E-J.; Kim, S-J.; J. Solid State Chem. 2001, 160, 195. 
11. Schleid, T.; Hartenbach, I.; Komm, T.; Z. Anorg. Allg. Chem. 2002, 628, 7.

12. Komm, T.; Schleid, T.; Z. Anorg. Allg. Chem. 2006, 632, 42.

13. Komm, T.; Schleid, T.; Z. Krystallogr. 2005, 22, 162.

14. Manríquez, V.; Galdámez, A.; Ruiz-León, D.; Garland, M.T.; Z. Kristallogr.-New Cryst. Struct. 2003, 218, 403.

15. Manríquez, V.; Galdámez, A.; Ruiz-León, D.; Garland, M.T.; Jiménez, M.; Z. Kristallogr.-New Cryst. Struct. 2003, $218,1$.

16. Manríquez, V.; Galdámez, A.; Ruiz-León, D.; Mater. Res. Bull. 2006, 41, 1337.

17. Manríquez, V.; Galdámez, A.; Guzmán, D.; Mater. Res. Bull. 2008, 43, 2469.
18. Barsoukov E.; Macdonald, J. R.; Impedance Spectroscopy, Theory, Experiment and Applications, $2^{\text {nd }}$ ed., Wiley: New York, 2005.

19. Hsu, C. S.; Mansfeld, F.; Corrosion 2001, 57, 747.

20. Van Vleck, H.; The Theory of Electric and Magnetic Susceptibilities, Oxford University Press: London, 1965.

21. Herpin, A.; Théorie du Magnétism, Presses Universitaires de France: Paris, 1968.
Received: September 25, 2008

Web Release Date: August 28, 2009 